\title{
Barriers to antenatal care during COVID-19 pandemic: A hospital-based retrospective cross-sectional study in rural south Karnataka
}

\author{
Philomena Zacharias, Merlyn Joseph, Ann Jacob, Mary Viji CL, Nitisha Ann Josy, \\ Shulia Lydia, Avita Rose Johnson
}

Corresponding author: Dr. Avita Rose Johnson, Department of Community Health, St. John's Medical College, Sarjapur Road, John Nagar, Bangalore, India; Email : avita@johnson.in

Distributed under Attribution-Non Commercial - Share Alike 4.0 International (CC BY-NC-SA 4.0)

\begin{abstract}
Background: As part of Covid-19 pandemic response, India went into lockdown to reduce transmission and prevent overwhelming of hospitals. Pregnant women need protection from Covid-19, while ensuring they receive antenatal care (ANC). Objectives: To assess barriers to ANC during Covid-19 pandemic lockdown in rural south Karnataka. Methods: Hospital-based, retrospective cross-sectional study among pregnant women availing ANC in June-July 2020, using a pre-tested interview schedule to capture barriers of access and fears during the pandemic lockdown of 22 March to 31 May 2020. Chi-square test performed to associate barriers to ANC with various independent covariates. Results: Of 144 pregnant women, $61.8 \%$ reported at least one barrier to accessing ANC, 38.9\% reported at least one fear and 85\% were not able to access ultrasounds and blood tests. Barriers were lack of income, lack of transportation and hospitals /diagnostic centres remaining closed. Barriers of fear were: getting infected with Covid19 , fear of not receiving proper treatment, fear of being turned away from hospital and fear of isolation from family. Women of lower socio-economic class and with pre-existing pregnancy complications were significantly more likely to experience barriers to ANC. Conclusion: Our study found that those residing in rural areas faced barriers to ANC as a result of a well-intentioned pandemic response. Community-based strategies, mechanisms for referral, health education and counselling through village-level workers may help to overcome these barriers. Policy makers must prioritize needs of pregnant women and address these barriers to ensure continued accessibility to ANC during any future pandemics.
\end{abstract}

Keywords: Covid-19, antenatal care, barriers of access, fears, pregnant women.

The spread of SARS-CoV-2 virus, causing Corona virus disease (Covid-19) was declared a global pandemic by World Health Organization on $11^{\text {th }}$ March 2020. ${ }^{1}$ India has crossed 4.4 million confirmed Covid-19 cases since the pandemic began, ${ }^{2}$ reaching third highest number of Covid-19 cases world-wide ${ }^{3}$ along with nearly 75,000 Covid-19related deaths. ${ }^{1}$ With rising number of cases, the population at risk of transmission includes those regularly visiting hospitals such as pregnant women. In order to reduce transmission, flatten the pandemic curve and prevent overwhelming of the health system, India went into a nation- wide lockdown from $22^{\text {nd }}$ March to $31^{\text {st }}$ May $2020 .^{4}$ While essential services were functioning and hospitals used this time to procure equipment and ramp-up infrastructure, ${ }^{5}$ nonCovid-19 patients, including pregnant women, faced difficulties in accessing care during this period. ${ }^{6}$

India has the largest number of pregnant women in the world and 20 million babies are projected to be born between March and December 2020. ${ }^{7}$ Hence, the huge challenge to protect pregnant women from being infected with Covid-19, while ensuring they still receive adequate antenatal care (ANC). Essential ANC includes early registration of

Received: $1^{\text {st }}$ October 2020, Peer review completed: $22^{\text {nd }}$ December 2020, Accepted: $28^{\text {th }}$ January 2021.

Zacharias P, Joseph M, Jacob A, Mary Viji CL, Josy NA, Lydia S, Johnson AR. Barriers to antenatal care during COVID-19 pandemic: A hospital-based retrospective cross-sectional study in rural south Karnataka. The New Indian Journal of OBGYN. 2021; 8(1): 27-32. 
pregnancy, monthly ANC visits, daily iron and folic acid (IFA) and calcium supplementation, screening and referral of high risk mothers and birth preparedness ${ }^{8}$. There is paucity of published literature to assess if these evidence-based measures to reduce maternal and perinatal mortality were compromised during Covid-19 pandemic lockdown. Documenting barriers faced by pregnant women in accessing essential ANC will enable us to strategize for preparedness in future pandemics, which would ensure essential ANC and prevent adverse maternal and perinatal outcomes. Two thirds of our population reside in rural areas, and therefore, this study was conducted in a rural area, to assess barriers faced by pregnant women to accessing ANC during Covid-19 pandemic lockdown. The data from this study will enable policy makers to design targeted interventions addressing these barriers, not only in the on-going Covid-19 pandemic, but also in preparedness for future pandemics.

\section{Methods}

A retrospective cross-sectional study was conducted at a secondary level maternity hospital in a village in Ramnagara District, Karnataka, located $60 \mathrm{Kms}$ from Bangalore city from June to July 2020. Study Population: Pregnant women attending antenatal clinic at the hospital. Sampling: In the absence of previous published literature, we assumed $50 \%$ of participants would encounter at least one barrier to ANC during lockdown. With 95\% confidence level, 10\% absolute precision and assuming $20 \%$ non-response rate, we calculated sample size to be 116 . However, as data was collected by several researchers simultaneously, estimated sample size was exceeded. Consecutive sampling technique was employed.

Inclusion criteria: Antenatal women who were pregnant prior to $22^{\text {nd }}$ March 2010, when the nation-wide Covid-19 lockdown began. Exclusion criteria: Those with labour pains, seriously ill or with mental health conditions that prevented them from understanding and responding to questions.

A pre-tested, face-validated, structured interviewschedule, translated in Kannada, consisting of three parts: i) socio-demographic and obstetric details, including Modified BG Prasad's Socio-economic classification. ${ }^{9}$ Complications in pregnancy were noted down from ANC records. ii) utilisation of essential ANC services during lockdown $\left(22^{\text {nd }}\right.$ March to $31^{\text {st }}$ May 2020) iii) barriers to essential ANC during lockdown, identified from extensive review of literature of barriers to care, consisting of two domains: barriers to access ( 8 items) and barriers of fear ( 8 items).
Outcome variables: Barrier to access (presence of any one barrier to access) and barrier of fear (presence of any one barrier of fear). Approval from Institutional Ethics Committee obtained. Written informed consent taken from all participants prior to administering the study instrument.

Statistical Analysis: Data was analysed using IBM Statistical Package for Social Sciences version 20. Study variables were described as frequencies, proportions, mean, standard deviation, median and interquartile range, as applicable. Outcome variables were associated with independent co-variates using Chi-square test. Data are presented as tables and graphs. $\mathrm{P}$ value of $<0.05$ was considered as statistically significant for all analyses.

\section{Results}

A total of 144 pregnant women participated in the study, with mean age of $24.0 \pm 3.5$ years. Mean number of years of formal education was $12.7 \pm 2.5$. Majority (91\%) were homemakers, Hindu by religion (93\%) and studied at preuniversity or higher. $56.9 \%$ were rural dwelling, with $43.1 \%$ from the near-by town. Most were from joint family $(80.6 \%)$, with median monthly per capita income of INR 3,333 (2500, 5000) Rs.

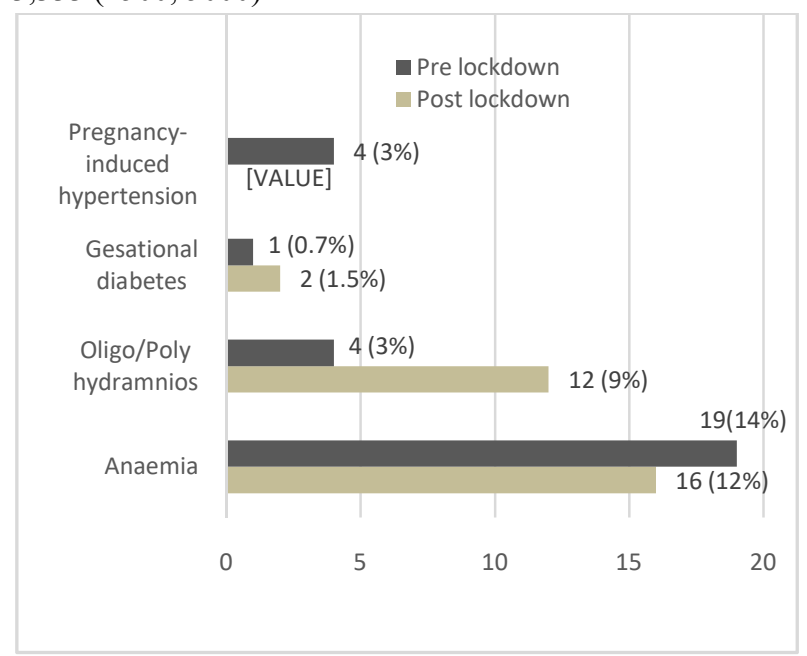

Figure 1: Complications in pregnancy before and after lockdown among women in the second and third trimesters $(\mathrm{N}=133)$ Most $108(75 \%)$ were in third trimester of pregnancy, $31(21.5 \%)$ in second and $5(3.5 \%)$ in first. All subjects were pregnant when the lockdown began. Most were primigravidae (62\%). Bad obstetric history (previous abortions/stillbirths/infant deaths) was reported by 28(19.4\%). Complications in pregnancy before and after lockdown among women in second and third trimesters were 
The New Indian Journal of OBGYN. 2021 (July-December);8(1)

Table 1: Association of barriers of access to ANC and barriers of fear with various independent covariates ( $N=144)$

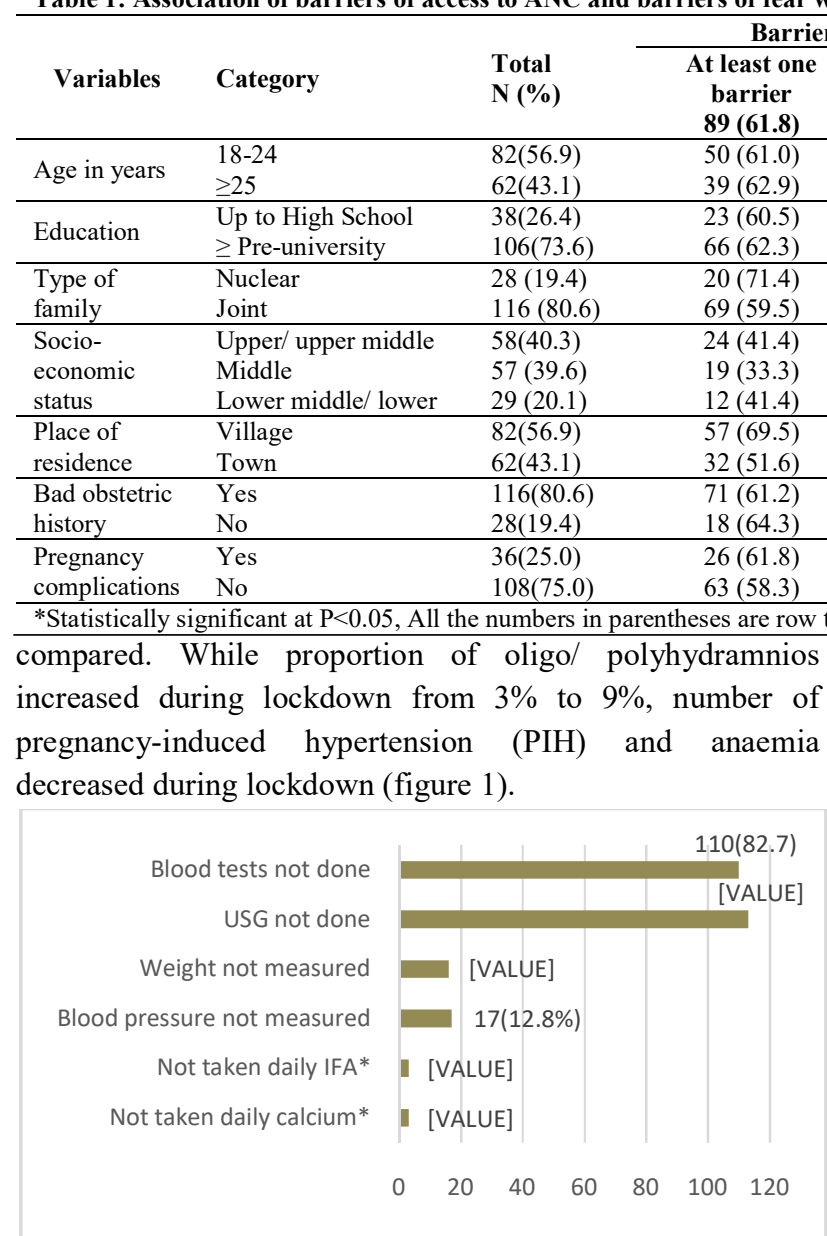

Figure 2: Inability to access essential ANC during lockdown ( $N=144)$

Most pregnant women in our study reported not being able to access blood tests or ultrasounds (85\%) during lockdown, $12 \%$ could not get their blood pressure and weight checked. Nearly all (97\%) continued to have access to iron and calcium supplementation. None had access to any telemedicine services.

Commonest barriers faced by pregnant women to accessing ANC during Covid-19 pandemic lockdown were: lack of income (45\%), lack of availability of cash / access to ATM (40\%), usual hospital being closed (14\%), lack of a vehicle for transportation (12\%), lack of family support to go for ANC (12\%) and laboratories being closed (11\%) (figure 2). Nearly two thirds $(61.8 \%)$ reported at least one barrier to accessing ANC. Barriers to access was significantly associated with living in the nearby town (table 1).
The New Indian Journal of OBGYN. 2021 (July-December);8(1)

\begin{tabular}{|c|c|c|c|c|}
\hline ccess & & Barri & fear & \\
\hline $\begin{array}{c}\text { No } \\
\text { Barriers } \\
55 \text { (38.2) }\end{array}$ & $\begin{array}{c}P \\
\text { value }\end{array}$ & $\begin{array}{c}\text { At least one } \\
\text { barrier } \\
56(38.9)\end{array}$ & $\begin{array}{c}\text { No } \\
\text { Barriers } \\
88(61.1) \\
\end{array}$ & $\begin{array}{l}P \\
\text { value }\end{array}$ \\
\hline $\begin{array}{l}32(39.0) \\
23(37.1)\end{array}$ & 0.814 & $\begin{array}{l}35(42.7) \\
21(33.9)\end{array}$ & $\begin{array}{l}47(57.3) \\
41(66.1)\end{array}$ & 0.283 \\
\hline $\begin{array}{l}15(39.5) \\
40(37.7)\end{array}$ & 0.850 & $\begin{array}{l}11(28.9) \\
45(42.5)\end{array}$ & $\begin{array}{l}27(71.1) \\
61(57.5)\end{array}$ & 0.143 \\
\hline $\begin{array}{c}8(28.6) \\
47(40.5)\end{array}$ & 0.243 & $\begin{array}{l}13(46.4) \\
43(37.1)\end{array}$ & $\begin{array}{l}15(53.6) \\
73(62.9)\end{array}$ & 0.362 \\
\hline $\begin{array}{l}34(58.6) \\
38(66.7) \\
17(58.6) \\
\end{array}$ & 0.624 & $\begin{array}{l}28(48.3) \\
42(73.7) \\
18(62.1)\end{array}$ & $\begin{array}{l}30(51.7) \\
15(26.3) \\
11(37.9)\end{array}$ & $0.020^{*}$ \\
\hline $\begin{array}{l}25(30.5) \\
30(48.4)\end{array}$ & $0.028 *$ & $\begin{array}{l}38(46.3) \\
18(29.0)\end{array}$ & $\begin{array}{l}44(53.7) \\
44(71.0) \\
\end{array}$ & $0.034^{*}$ \\
\hline $\begin{array}{l}45(38.8) \\
10(35.7)\end{array}$ & 0.763 & $\begin{array}{l}44(37.9) \\
12(42.9)\end{array}$ & $\begin{array}{l}72(62.1) \\
16(57.1)\end{array}$ & 0.631 \\
\hline $\begin{array}{l}10(27.8) \\
45(47.7)\end{array}$ & 0.137 & $\begin{array}{l}19(52.8) \\
37(34.3)\end{array}$ & $\begin{array}{l}17(47.2) \\
71(65.7)\end{array}$ & $0.048^{*}$ \\
\hline
\end{tabular}

Participants also reported various fears, which prevented them from accessing ANC during the lockdown: fear of getting infected with Covid-19 (34\%), fear of not receiving

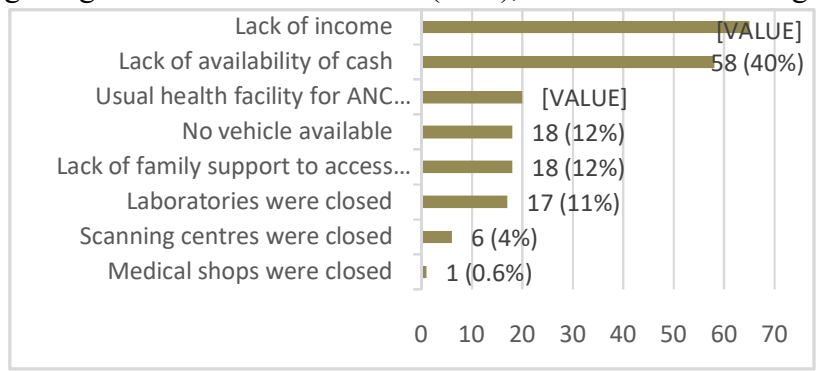

Figure 3: Barriers of access to ANC faced by pregnant women during the Covid-19 pandemic lockdown $(\mathrm{N}=144)$

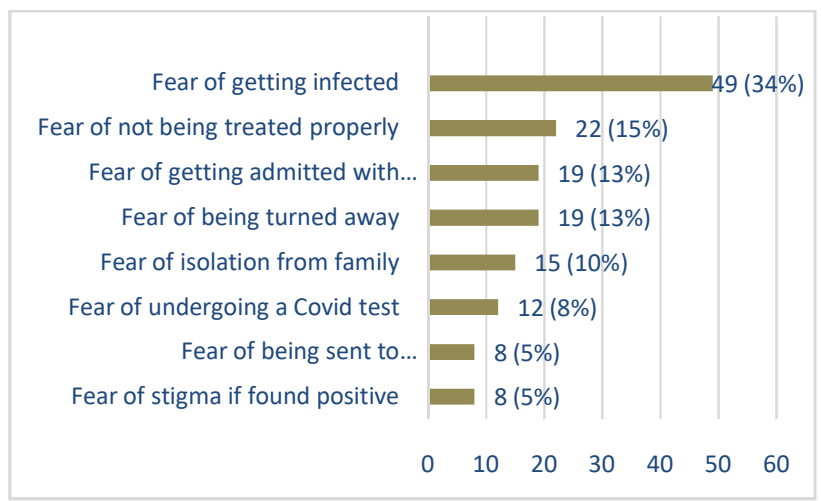

Figure 4: Barriers of fears affecting ANC as reported by pregnant women during the Covid-19 pandemic lockdown ( $N=144)$. proper treatment (15\%), fear of getting admitted with Covid19 , fear of being turned away from the hospital (13\%) and fear of isolation from family (10\%) (figure 3). More than one-third $(38.9 \%)$ of our study subjects reported at least one 
fear that was a barrier to accessing ANC. Barrier of fear was significantly associated with low socio-economic status $(\mathrm{P}=0.02)$, town-dwelling women $(\mathrm{P}=0.001)$ and those with known pregnancy complications prior to lockdown $(\mathrm{P}=0.048)($ table 1$)$.

\section{Discussion}

A key component of pandemic preparedness involves addressing needs of pregnant women, who face a unique conundrum, whether to seek regular ANC and risk getting infected, or stay away from the health system and risk developing complications.

Our study reported several barriers to ANC during the Covid -19 pandemic lockdown. The biggest fear among pregnant rural women in our study was the fear of getting infected with Covid -19. Pregnant women in urban areas too have reported a fear of contracting the virus during visits to hospital for ANC. ${ }^{10}$ This is a justified fear, as it has been found that pregnant women are more likely to suffer complications of Covid -19. A recent report from the US Centers for Disease Control and Prevention (CDC), found $31.5 \%$ of pregnant women with Covid -19 were reported to have been hospitalized compared to just $5.8 \%$ of nonpregnant women. Pregnant women were more likely to be admitted to the $\operatorname{ICU}[\mathrm{aRR}=1.5(1.2-1.8)]$ and receive mechanical ventilation $[\mathrm{aRR}=1.7(1.2-2.4)]$ for Covid -19 complications. ${ }^{11}$

Pregnant women in metropolitan cities have been instructed by obstetricians to monitor blood pressure, blood sugar and baby movements at home and use telemedicine (teleconsultation) services. ${ }^{10}$ However, in our study setting, none had access to any teleconsultation. Lack of access to digital devices and wifi/internet can be additional barriers for women in rural communities. Common pandemic preparedness strategies to reduce transmission may seem outwardly fair and neutral, but create disparities when applied in unequal socio-cultural contexts like urban /rural, rich/poor or digitally-savvy/illiterate. Therefore, socialdistancing strategies such as tele-consultation for avoidance of hospitals may not be a realistic option for rural pregnant women.

Subjects in our study reported not being able to access blood tests or ultrasounds during lockdown. Though numbers were small, we found that the proportion of oligohydramnios and polyhydramnios increased during lockdown. This could be attributed to lack of early detection via ultrasounds. Inability to access ultrasounds has been similarly reported by pregnant women during lockdown in other states of India as well as other countries across the globe. ${ }^{12,} 13$ While healthcare providers felt obligated to postpone ultrasounds to avoid risk of infection to pregnant women, the fact remains that adverse conditions may remain undiagnosed. $^{14}$ Also, anomaly scans typically carried out between 18 to 22 weeks of gestation, is a narrow window of opportunity that may have been missed out. Access to essential components of ANC like blood pressure and weight measurement was also hampered during lockdown. These points out that healthcare facilities need to develop strategies to ensure that pregnant women receive essential ANC, but with minimal exposure to Covid-positive cases. In addition, plans for care and delivery of pregnant women with confirmed Covid-19 must ensure that these women receive appropriate care without exposing other healthy pregnant women to risk of infection.

Surprisingly the numbers of pregnancy-induced hypertension (PIH) and anaemia slightly reduced during lockdown. Though this number was too small to draw definite conclusions, we can attribute this to families being together at home, giving pregnant women additional emotional support and help, which may have reduced stress and household chores, thereby decreasing blood pressure. Nearly all women in our study reported being adherent to iron supplementation during lockdown. Though our study design did not allow for further exploration qualitatively, we surmise that family support during lockdown could have also contributed to adherence and thereby decreased anaemia.

Outbreaks of infectious disease tend to highlight barriers to healthcare ranging from lack of access due to geographic distance, to high costs which dissuade individuals from seeking care. These barriers disproportionately affect those who are already vulnerable including rural and low income individuals. The commonest barriers to accessing ANC during lockdown faced by pregnant women in our study were: lack of income, lack of availability of cash / access to an ATM and lack of transportation. Women residing in the nearby town faced transportation barriers due to strict measures that prevented easy movement of vehicles. Women from low socio-economic class were also found to face barriers to ANC. The Minnesota Pandemic Ethics Project (MPEP also identified similar access barriers in communities in USA: lack of transportation and distance to care, ${ }^{15}$ with financial burden of healthcare cited as a challenge for those without private or public insurance. In our study too, lack of income during the pandemic was an issue, considering that in our rural study setting, those engaged in agrarian 
occupations are mostly daily wage earners. This indicates that it is necessary while planning for pandemic preparedness to ensure that social and financial factors do not interfere with the ability to receive healthcare. ${ }^{16}$ Preventive strategies during pandemics may exacerbate risks for vulnerable populations like lower-income rural women who need ANC the most, but also face the most barriers to ANC. Rather than ameliorating structural inequalities, pandemic preparedness strategies sometimes contribute to them. ${ }^{15}$

The rural women in our study reported various fears, which acted as barriers to accessing ANC during the lockdown: fear of getting infected with Covid-19, fear of not receiving proper treatment, fear of being turned away from hospital and fear of isolation from family. These fears were significantly associated with residing in the near-by town, as compared to villages. This may have been because communities residing in towns have more access to information, forwarded messages on smart phones, access to TV and media reporting on Covid-19 which may have played a role in increasing apprehensions and fears, along with rising number of cases in the urban area. Women with known pregnancy complications prior to lockdown were also significantly more likely to have barriers of fears, probably due to apprehensions of not being able to access care in case of emergency and worries of worsening of complications or adverse outcomes. Fears during pandemics may exacerbate the usual level of stress and anxiety that is experienced in pregnancies. ${ }^{17}$ This reveals a need for support mechanisms and counselling services to alleviate unnecessary stress on the mother.

Though our study found that lock-down measures during the Covid-19 pandemic did not create insurmountable barriers to access, our findings are still aligned with reports from developed countries, that show that socially disadvantaged rural populations can become more burdened by public health response interventions than relatively privileged populations. A pragmatic social justice approach, addressing both health disparities and access barriers, should influence pandemic preparedness. ${ }^{[18]}$ Community support in the form of women's groups, along with referral and counselling through mechanisms involving village-level workers, can help overcome barriers of fear. Policy makers need to counter the social injustice of structural inequalities and adequately meet needs of vulnerable groups, therefore pandemic preparedness efforts must address both health disparities and access barriers. Side-lining maternal health in the wake of Covid-19 may give rise to a parallel health disaster. In a crisis situation such as now, meticulous planning, focussing on availability and accessibility of essential ANC is of utmost importance to prevent adverse maternal and perinatal outcomes.

The study design being hospital-based, we could not capture data from women in the community, who might still be facing barriers to ANC even in the 'unlock phase'. As this was a retrospective study with questions pertained to events that occurred a month or two prior, there might have been possibility of recall bias. The lack of qualitative methodology also prevented us from exploring further into issues of fears and barriers to accessing ANC.

\section{Conclusion}

Our study identified several barriers to accessing ANC during the Covid-19 pandemic lockdown such as lack of income, lack of transportation and hospitals /diagnostic centres being closed. Barriers of fear which hindered ANC were fear of getting infected with Covid-19, fear of not receiving proper treatment, fear of being turned away from the hospital and fear of isolation from family. Women residing in the town, of lower socio-economic class, and those with pre-existing pregnancy complications were significantly more likely to experience barriers to ANC.

\section{Conflict of interest: None. Disclaimer: Nil.}

\section{References}

1. Cucinotta D, Vanelli M. WHO declares Covid-19 a pandemic. Acta Biomed. 2020; 91: 157-60.

2. Active cases, Covid19 India. Available from : https:// www.covid19india.org [Last accessed 2020 Sept 8]

3. WHO Situation Report $24^{\text {th }}$ June 2020; Coronavirus disease (Covid-19) Situation Report - 156; Data as received by WHO from national authorities by 10:00 CEST, 24 June 2020 Available from: https:/ www.who.int/docs/default-source/coronaviruse/ situation-reports/20200624-covid-19-sitrep-156.pdf? sfvrsn=af42e480_2 [Last accessed 2020 Aug 1]

4. Covid-19: Lockdown across India, in line with WHO guidance. UN News, 2020 Mar 24. Available from: https://news.un.org/en/story/2020/03/1060132 [Last accessed 2020 Aug 1]

5. Govt says lockdown period used to ramp up health infrastructure required for Covid-19 management. 2020 May 27 . Available from: https://www.dnaindia.com/ india/report-govt-says-lockdown-period-used-to-ramp- 
The New Indian Journal of OBGYN. 2021 (July-December);8(1)

up-health-infrastructure-required-for-covid-19management-2826176 [Last accessed 2020 Aug 1]

6. Jain AM. Pregnant during Covid-19: Expecting mothers left in the lurch by India's healthcare system as tackling pandemic takes priority. 2020 June 12. Available from: https://www.firstpost.com/health/pregnant-during-covid19-expecting-mothers-left-in-the-lurch-by-indiashealthcare-system-as-tackling-pandemic-takes-priority8476401.html [Last accessed 2020 Aug 24]

7. PTI. At 20.1 million, India expected to have highest births since Covid-19 declared as pandemic: UNICEF 2020, May 07 Available from: https://www. financialexpress.com/lifestyle/health/two-crore-babiessince-lockdown-india-to-record-highest-number-ofbirths-under-covid-19-shadow-unicef/1950775/[Last accessed 2020 Aug 24]

8. My Safe Motherhood. Booklet for Expecting Mothers. Maternal Health Decision. Ministry of Health and Family Welfare, Government of India. Available from : https://nhm.gov.in/images/pdf/programmes/maternalhealth/guidelines/my_safe_motherhood_booklet_ english. pdf [Last accessed 2020 Aug 4]

9. Debnath DJ. Kakkar R. Modified BG Prasad Socioeconomic Classification, Updated - 2020. Indian J Comm Health. 2020;32:124-125

10. Jaiswal PB. Pregnancy and its challenges in times of Covid-19. The Week. 2020 April 3. Available from: https://www.theweek.in/news/health/2020/04/03/pregna ncy-and-its-challenges-in-times-of-covid-19.html [Last accessed 2020 Sept 1]

11. Hartnett KP, Kite-Powell A, DeVies J, Coletta MA, Boehmer TK, Adjemian J, et al. Impact of the Covid-19 pandemic on emergency department visits: United States, January 1, 2019 to May 30, 2020. Centers for Disease Control and Prevention. Morbidity and Mortality Weekly Report. 2020 Jun 12; 69(23): 699-704

12. Access to maternal health care: challenges with lockdown. SAMA Resource group for Women and Health 2020. Available from: http://www. samawomenshealth.in/access-to-maternal-health-carechallenges-with-lockdown/ [Last accessed 2020 Sept 1]

13. Pregnancy in times of lockdown: overcoming fears and keeping on going. UNICEF 2020. Available from: https://www.unicef.org/ukraine/en/stories/pregnancytimes-lockdown-overcoming-fears-and-keeping-going [Last accessed 2020 Sept 4]
14. Matta A. Lack of Pre-Natal, Hospital Care Have Left Pregnant Women Helpless During Lockdown. The Swaddle. 2020 May 26. Available from : https://heswaddle.com/lack-of-pre-natal-hospital-carehave-left-pregnant-women-helpless-during-lockdown/ [Last accessed 2020 Sept 4]

15. DeBruin D, Liaschenko J, Marshall MF. Social justice in pandemic preparedness. Am J Public Health 2012;102:586-91.

16. Andrada C. Addressing barriers to care: a must for outbreak detection and response. Outbreak Observatory, Johns Hopkins Bloomberg School of Public Health. 2020 Mar 12.Available from: https://www. outbreakobservatory.org/outbreakthursday-1/3/12/2020/ addressing-barriers-to-care-a-must-for-outbreakdetection-and-response [Last accessed 2020 Sept 4]

17. Getting pregnant during the pandemic: Covid-19, pregnancy and fertility. Extend Fertility. 2020 July 24 Available from: https:/extendfertility.com/coronaviruscovid-19-pregnancy-fertility/ [Last accessed 2020 Sept 8]

18. Covid-19 FAQs: health equity in a pandemic. American Medical Association. 2020 Jul 28. Available from: https://www.ama-assn.org/delivering-care/healthequity/covid-19-faqs-health-equity-pandemic

\footnotetext{
Philomena Zacharias ${ }^{1}$, Merlyn Joseph ${ }^{2}$, Ann Jacob ${ }^{3}$, Mary Viji CL ${ }^{4}$, Nitisha Ann Josy ${ }^{5}$, Shulia Lydia ${ }^{6}$, Avita Rose Johnson ${ }^{7}$

${ }^{1}$ Postgraduate student, Department of Community Health, St. John's Medical College, Bangalore, Karnataka, India; ${ }^{2}$ Tutor, Department of Community Health, St. John's Medical College, Bangalore, Karnataka, India; ${ }^{3}$ Intern, Department of Community Health, St. John's Medical College, Bangalore, Karnataka, India; ${ }^{4}$ Intern, Department of Community Health, St. John's Medical College, Bangalore, Karnataka, India; ${ }^{5}$ Intern, Department of Community Health, St. John's Medical College, Bangalore, Karnataka, India; ${ }^{6}$ Intern, Department of Community Health, St. John's Medical College, Bangalore, Karnataka, India; ${ }^{7}$ Department of Community Health, St. John's Medical College, Bangalore, Karnataka, India.
} 